\title{
Antibiotic Susceptibility Profile of Bacterial Isolates from Commercial Poultry Farms in Ile-Ife, Nigeria
}

\author{
Fatokun Evelyn Nwadinkpa ${ }^{*}$, Fakorede Cecilia Nireti, Atobatele Kofoworola Zainab \\ Department of Biological Sciences, College of Natural and Applied Sciences, Oduduwa University, Ipetumodu, Nigeria \\ Email address: \\ evelyn.fatokun@oduduwauniversity.edu.ng (F. E. Nwadinkpa), fakorede.c@oduduwauniversity.edu.ng (F. C. Nireti), \\ zaynabkofo@gmail.com (A. K. Zainab) \\ *Corresponding author
}

\section{To cite this article:}

Fatokun Evelyn Nwadinkpa, Fakorede Cecilia Nireti, Atobatele Kofoworola Zainab. Antibiotic Susceptibility Profile of Bacterial Isolates from Commercial Poultry Farms in Ile-Ife, Nigeria. Chemical and Biomolecular Engineering. Vol. 6, No. 3, 2021, pp. 59-67.

doi: $10.11648 /$ j.cbe. 20210603.13

Received: July 26, 2021; Accepted: August 18, 2021; Published: September 29, 2021

\begin{abstract}
Nontherapeutic antimicrobial usage in animal farms has been associated with the development and spread of resistant bacteria. The emergence of serious life-threatening infections from veterinary and environmental sources and treatment failures occurring with the available antibiotics warrants investigation into resistance of antimicrobial agents in poultry farms. This study therefore provides information on antibiotic resistance pattern of bacteria isolated from five commercial poultry farms in Ile Ife, a peri-urban settlement in Nigeria. Isolation of bacteria from droppings, feed and water samples, was performed by spread plate method using all purpose and selective media. Morphological and biochemical characterization of isolates was done. The antibiotics sensitivity of the recovered isolates was determined by Kirby-Bauer disk diffusion method. A total 151 bacterial isolates, comprising 11 genera of 8 Gram negative and 3 Gram positive bacteria were recovered. E. coli had highest incidence rate of $21.19 \%$, followed by Bacillus sp. with $15.23 \%$; while the least recorded incidence of $1.32 \%$ was Citrobacter sp. All five farms recorded a 100\% resistance to at least two (2) classes of antibiotics. A 100\% resistance was recorded for augmentin in all five (5) farms, while 100\% resistance in four (4) farms was recorded for cloxacilin. Furthermore a 100\% resistance against erythromycin and cefixime respectively was documented in three farms. The least percentage resistance of $30 \%$ was against ciprofloxacin in only one farm, while the overall highest susceptibility of $39 \%$ was to ofloxacin. The multiple antibiotic resistance index (MARI) of isolates from all farms ranged from 0.3 to 1 . Up to 9 bacterial genera had MARI 1, including E. coli, Salmonella, Bacillus, Klebsiella, and Pseudomonas. This study is a further indication that poultry farms represents an important reservoir of antibiotic resistance bacteria. It also serves as a pointer to the need for enforcement of regulatory antibiotics use in poultry farming by the government, and controlled usage by all stakeholders.
\end{abstract}

Keywords: Antibiotic, Resistance, Susceptibility, Bacteria, Poultry Farm, MARI

\section{Introduction}

There is an increasing demand for poultry meat mainly due to its acceptance by most societies and its relatively low cholesterol content and egg products [1]. Food and Agriculture Organization (FAO) reported a global increase in egg and poultry meat production, with a total of 87 million tons of eggs and 123 million tons of poultry meat $(37 \%$ of meat production) in 2017 [2]. The poultry sub-sector is the most commercialized of all of Nigeria's agricultural sub-sectors; poultry meat and eggs being among the main source of protein in many households [3].
Domestic chickens are the most important poultry species in the world; contributing $89 \%$ of world poultry meat production [2]. However increasing world populations and urbanization have led to the bulk of production being in larger, more intensive specialist units. These are often situated close to where the feed is grown or to where the meat is needed, and result in cheap, safe food being made available for urban communities [4]. All over the world, more than 300 breeds of domestic chicken species (Gallus domesticus) exist [4]. There are basically three types of chicken. They are:

1) Layers: these are reared for egg production.

2) Broilers: are reared for meat production and are ready for 
market from 8 weeks.

3) Cockerel: This is also reared for meat production. Cockerels grow slower and can take up to twenty four weeks before they are matured for marketing. Cockerels are reliable in terms of survival and withstanding bad weathers. They are more resilient, and can absorb shock far better than layers and broilers.

Nigeria has the second largest chicken population in Africa As a result, livestock in these environments commonly require aggressive infection management strategies, which often include the use of antibiotic therapy [5]. Most commercial farmers in particular, rearing chicken for meat or egg production, do so under intensive management system [6]. Under that condition antibiotics are used as therapeutic agents, prophylactic agents and growth promoters in feed [7]. It is to be stressed that in animals the antimicrobial agents are not used only for therapy and prevention of bacterial infections but also as growth promoters. In Europe, approximately 30\% of all antibiotics used in animals are growth promoters [8]. Some of the commonly used antibiotics today in poultry industries in developing countries like Nigeria are tylosine, neomycin, gentamycin, tetracyclines (chlortetracycline, oxytetracycline), sulfonamides (sulfadimethoxine, sulfamethazine, sulfathoxazole), penicillin (ampicillin), arsenicals (roxarsone), enrofloxacin, erythromycin and vaccines [9].

There is growing scientific evidence that the use of antibiotics in food animals leads to the development of resistant pathogenic bacteria that can reach humans through the food chain [10]. The concern over microbial antibiotic resistance has led to the banning of antibiotic use in feeds for poultry and livestock in various countries of Europe as well as in the U.S.A [11]. It is now generally known that the main risk factor for an increase in bacterial resistance is an increased use of antibiotics, it is similar in humans and in animals [12]. These drug resistant bacteria can move from animals to humans through a variety of channels, the farmers, their families, or employees through direct contact with animals, their neighbors, or others through soil and water contamination or via airborne particles and consumers via contaminated meat. Bacteria also pass resistance genes back and forth, creating another mechanism by which antibiotic resistance could be transferred to human pathogens [13]. This study therefore provides information on antibiotic resistance pattern of bacteria isolated from droppings, feed and water samples, in commercial poultry farms in Ile-Ife, Osun State, Nigeria. The specific objectives were to isolate bacteria from poultry droppings, feed and water samples; characterize isolates based on morphological and biochemical tests, and carry out antibiotic susceptibility testing on the isolates.

\section{Materials and Methods}

\subsection{Study Area}

This study was carried out in Ile-Ife of Osun State, in the South-West region of Nigeria. Ile-Ife is a semi-urban town with two Local Government Areas, namely; Ife East and Ife Central. Geographically, Ile-Ife lies on longitude $4^{\circ} 69^{\prime} \mathrm{E}$ and latitude $70^{\circ} 50^{\prime} \mathrm{N}$ and has a humid tropical climate with distinct wet and dry seasons. Ile-Ife is an ancient town in Yoruba history of Western Nigeria, and is regarded as the cradle of civilization [14]. Conventional farming system is practiced by the populace.

\subsection{Collection of Sample}

Composite samples of water and feed in canisters and/or troughs, and chicken droppings were collected from 5 different commercial poultry farms in the months of April to June, 2019. These farms are distributed within Ile-Ife, Osun State in different districts (Table 1) namely Obafemi Awolowo University (OAU) campus (OAU farm), Sabo (Olabisi Farm), Opa (Adedapo farm), Adesanmi (Abdulrahman farm) and NASFAT (Rukol farm). The feed and droppings samples were collected in sterile ziplock bags using spatula, and water samples were collected in sterile bottles. All samples were immediately transported in ice packs to Oduduwa University microbiology laboratory for analysis.

Table 1. Description of the poultry farms.

\begin{tabular}{ll}
\hline SITE CODE & DESCRIPTION \\
\hline A & This farm is a tertiary institution farm. A total of 1500 birds were in the poultry, which were all broilers kept in folds. Neomycin, \\
& Enrofloxacin were the major antibiotics used in the poultry farm \\
B & Is a private farm located in SABO, Ile-Ife. A total of 300 birds were kept in the poultry, which were all broilers reared in deep liter system. \\
& Antibiotics used were Tylodox, Keproceryl, tetracycline and doxygen. \\
This is a private owned poultry farm located at OPA, Ile-Ife. A total of 800 birds were kept in the poultry, which were all broilers reared in \\
folds. Keproceryl, Cotrimoxazole and Neomycin were the antibiotics used. \\
This poultry is a private farm located at ADESANMI Ile-Ife Osun state. A total of 1000 birds were kept in the farm, which were all \\
broilers kept in folds. The antibiotics used in the farm were Kenflux, Enrofloxacin and Cotrimoxazole. \\
E & $\begin{array}{l}\text { The poultry is a private farm located at NASFAT Ile-Ife Osun state. A total of } 500 \text { birds were reared, which were kept in folds. Antibiotics } \\
\text { used in the farm were Neomycin, Enrofloxacin and Cotrimoxazole }\end{array}$ \\
\hline
\end{tabular}

\subsubsection{Preparation of Media Used}

The media were aseptically prepared according to the manufacturer's instructions. All media were sterilized by autoclaving at $121^{\circ} \mathrm{C}$ for 15 minutes except Salmonella Shigella agar (SSA) which was heated to boiling point.

\subsubsection{Microbiological Analysis}

For the isolation of total heterotrophic bacteria. A $1 \mathrm{~g}$ sample each of feed or droppings, was dissolved thoroughly in $9 \mathrm{ml}$ of peptone water and used in preparing fivefold serial dilutions. For water sample, $1 \mathrm{ml}$ of each sample was added in 
$9 \mathrm{ml}$ of peptone water and used to prepare fivefold serial dilutions. A fresh sterile tip was used to mix the contents of each dilution by sucking up and down several times, then 0.1 $\mathrm{ml}$ of each dilution for $10^{2}$ to $10^{5}$ was withdrawn and inoculated into nutrient agar (NA) plates, using spread plate method. A $10^{1}$ and $10^{2}$ dilutions were streaked on eosin methylene blue agar (EMB) agar for isolation of E. coli, and on SSA for isolation of Salmonella and Shigella. Two replicates of each dilution were made and were labeled. Inoculated plates were incubated in an inverted manner for $18 \mathrm{~h}$ to $24 \mathrm{~h}$ at $37^{\circ} \mathrm{C}$. The plates were observed, counted and the distinct colonies were re-streaked on the respective medium in order to obtain pure culture which were stored in nutrient agar slants at $4^{\circ} \mathrm{C}$ for further test.

\subsubsection{Morphological and Biochemical Identification of Isolates}

Gram staining was performed on microbial pure culture to differentiate organisms based on their cell wall structure [15]. Bacterial isolates were further identified based on their cultural, morphological and biochemical characteristics according to Bergey's Manual of Determinative Bacteriology [16]. Biochemical characteristics were determined using conventional biochemical tests such as methyl red-voges-Proskauer, catalase, indole and citrate tests [17].

\subsection{Antibiotic Susceptibility Tests (AST)}

The antibiotic susceptibility pattern of all the isolated bacteria from each farm was determined using the disk diffusion method according to the Bauer - Kirby technique [18]. A colony of pure isolate to be tested was picked with a sterile wire loop and was aseptically dissolved in $5 \mathrm{ml}$ sterile saline solution. It was mixed thoroughly and repeated until the turbidity of the saline solution visually matched that of 0.5 McFarland standard. A sterile swab was dipped into the saline solution of the isolate and was gently squeezed against the inside of the tube i $\mathrm{n}$ order to remove excess fluid. The swab was used to streak all through the surface Mueller Hinton agar plates to ensure a lawn of growth. After the streaking was completed, the plate was allowed to dry for 5 minutes. The Antibiotic discs used are presented in Table 2. The discs were placed on the surface of the agar using sterilized forceps and were gently pressed onto the surface of the agar. The inoculated plates was carefully inverted and incubated for 24 hours at $37^{\circ} \mathrm{C}$. After incubation, a metric ruler was used to measure the diameter of the zone of inhibition for each antibiotic used. Zone of inhibition was interpreted according to the interpretative standard of the Clinical and Laboratory Standards Institute guidelines [18].

Table 2. Antibiotics discs used and the concentration

\begin{tabular}{lll}
\hline S/N & Antibiotic and its concentration & Antibiotic Class \\
\hline 1 & Amoxicillin/clavulanic acid (Augmentin/AUG- $30 \mu \mathrm{g})$ & Penicillins ( $\beta$-Lactams) \\
2 & Nitrofurantoin (NIT $-100 \mu \mathrm{g})$ & Nitrofurans \\
3 & Ciprofloxacin $(\mathrm{CIP}-5 \mu \mathrm{g})$ & Quinolones (Fluroquinolones) \\
4 & Cefuroxime $(\mathrm{CXM}-30 \mu \mathrm{g})$ & Cephalosporins \\
5 & Ceftriaxone $(\mathrm{CTR}-30 \mu \mathrm{g})$ & Cephalosporins \\
6 & Gentamicin $(\mathrm{GEN}-10 \mu \mathrm{g})$ & Aminoglycosides \\
7 & Erythromycin $(\mathrm{ERY}-5 \mu \mathrm{g})$ & Macrocyclics (Macrolides) \\
8 & Ofloxacin $(\mathrm{OFL}-5 \mu \mathrm{g})$ & Quinolones (Fluroquinolones) \\
9 & Cloxacilin $(\mathrm{CXC}-5 \mu \mathrm{g})$ & Penicillins ( $\beta$-Lactams) \\
10 & Cefixime $(\mathrm{CFM}-5 \mu \mathrm{g})$ & Cephalosporins \\
11 & Ceftazidime $(\mathrm{CAZ}-30 \mu \mathrm{g})$ & Cephalosporins \\
\hline
\end{tabular}

The multiple antibiotic resistance index (MARI), is defined as $\mathrm{a} / \mathrm{b}$ where;

' $a$ ' represents the number of antibiotics to which the isolate was resistant, and

' $b$ ' represents the number of antibiotics to which the isolate was exposed [19].

\subsection{Data Analysis}

Data collected were entered into Excel Spreadsheet. Descriptive statistics was used to examine resistance pattern in isolates and in the farms.

\section{Results}

\subsection{Total Heterotrophic Bacterial Count}

The total heterotrophic bacterial (THB) count of the poultry feed, water samples and droppings was noted and the result is presented in Table 3. The bacterial load of the samples showed that the highest heterotrophic bacterial count of feed samples was from Farm A with $2.01 \times 10^{7} \mathrm{cfu} / \mathrm{g}$, feed sample from Farm E came next with $1.56 \times 10^{7} \mathrm{cfu} / \mathrm{g}$ counts while the least count was recorded in Farm D with $1.46 \times 10^{7} \mathrm{cfu} / \mathrm{g}$. The THB count for water sample was highest in Farm D with $2.05 \times 10^{7} \mathrm{cfu} / \mathrm{ml}$, followed by Farm A with $1.92 \times 10^{7} \mathrm{cfu} / \mathrm{ml}$, the least recorded was in Farm $\mathrm{C}$ with a count of $1.4 \times 10^{7} \mathrm{cfu} / \mathrm{ml}$. However the highest THB in droppings of $2.40 \times 10^{5} \mathrm{cfu} / \mathrm{g}$ was recorded in Farm C. A higher count of $1.92 \times 10^{5} \mathrm{cfu} / \mathrm{g}$ was also recorded in Farm A, while the least THB count in droppings $1.46 \times 10^{5}$ was in Farm D.

\subsection{Morphological and Biochemical Tests Result}

The isolated bacteria were presumed to be Escherichia coli, Klebsiella sp., Bacillus sp. Staphylococcus sp., Proteus sp., Shigella sp., Salmonella sp., Enterobacter sp., Citrobacter sp., Pseudomonas sp. and Corynebacterium sp. These genera were recovered from the farms at varying frequency as indicated in Figure 1. The highest frequency of 32 was recorded for Escherichia coli with an incidence rate of $21.19 \%$, followed 
by Bacillus sp. with frequency of 23 isolates and an incidence of $15.23 \%$; while the least recorded frequency of 2 was
Citrobacter sp. with $1.32 \%$ incidence. The incidence rate is shown in Figure 2.

Table 3. Total heterotrophic bacterial count of the samples.

\begin{tabular}{llll}
\hline \multirow{2}{*}{ Sampling site } & Total Viable Count (cfu/g) & Total Viable Count (cfu/g) & Total Viable Count (cfu/ml) \\
\cline { 2 - 4 } & Droppings & Feed & water \\
\hline A & $1.92 \times 10^{5}$ & $2.01 \times 10^{7}$ & $1.92 \times 10^{7}$ \\
B & $1.85 \times 10^{5}$ & $1.20 \times 10^{7}$ & $1.85 \times 10^{7}$ \\
C & $2.40 \times 10^{5}$ & $8.9 \times 10^{7}$ & $1.4 \times 10^{7}$ \\
D & $1.46 \times 10^{5}$ & $1.46 \times 10^{7}$ & $2.05 \times 10^{7}$ \\
E & $1.60 \times 10^{5}$ & $1.56 \times 10^{7}$ & $1.64 \times 10^{7}$ \\
\hline
\end{tabular}

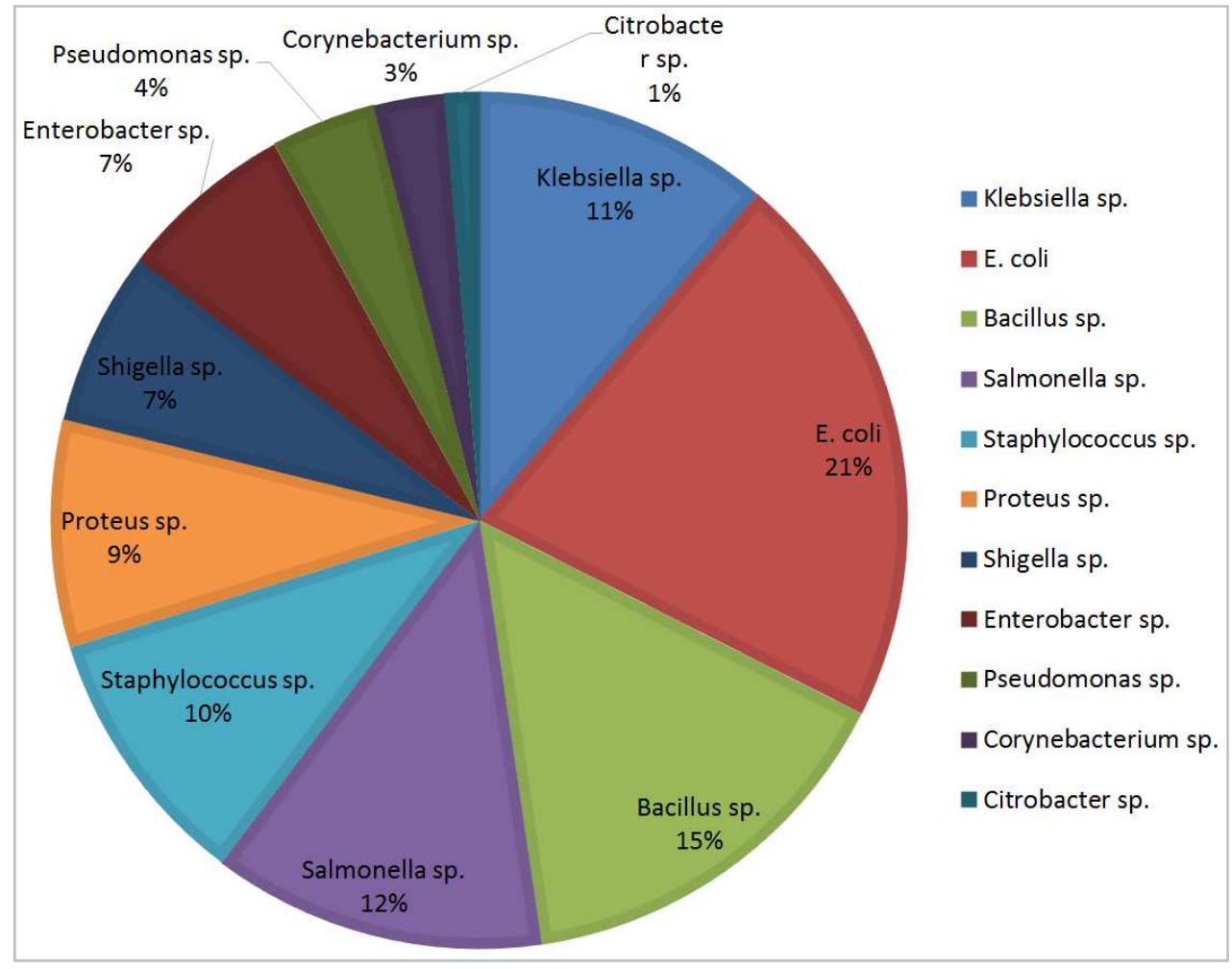

Figure 1. Frequency of the isolated bacteria.

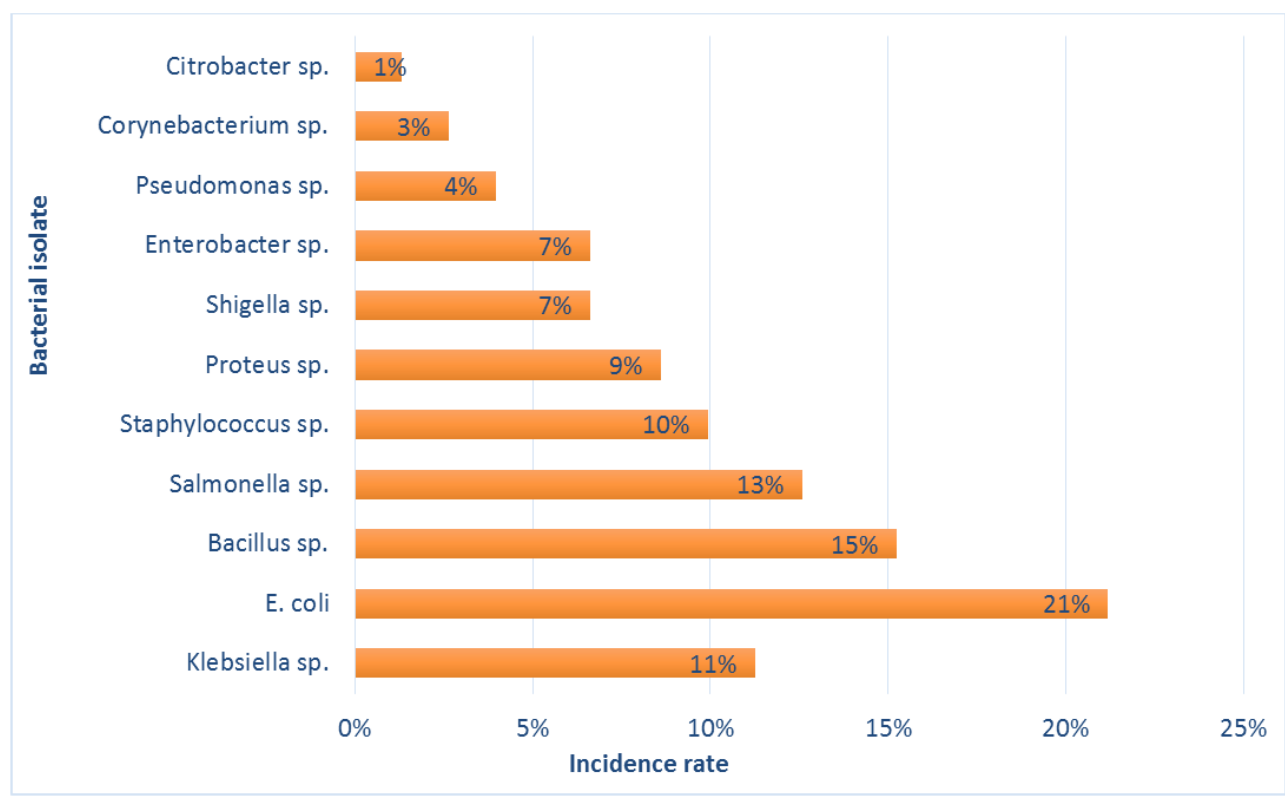

Figure 2. Incidence rate of bacterial isolates. 


\subsection{Antibiotics Susceptibility Profile}

Antibiotics susceptibility profile of the isolates from all farms indicated a susceptibility percentage (\%) of $39,38.4$ and 37 to ofloxacin, gentamicin and cefuroxime respectively. On the other hand, a highest resistance of $100 \%$ against augmentin, followed by $98 \%$ resistance against cloxacilin, cefixime and erythromycin respectively was recorded; while the least resistance of $44 \%$ was against ofloxacin. In addition, the intermediate reaction varied from $0 \%$ towards cloxacilin and augmentin respectively to $26 \%$ towards ciprofloxacin. Result of the susceptibility profile is presented in Figure 3.

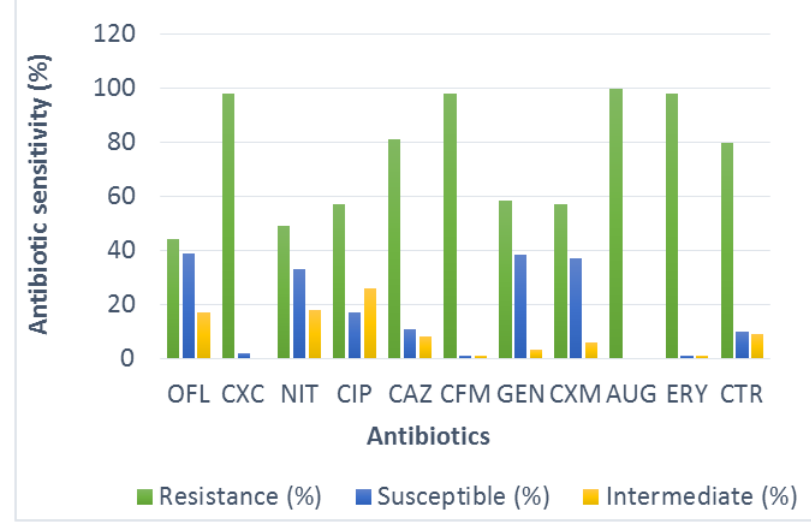

Figure 3. Susceptibility profile of isolates recovered from all farms.

The antibiotics resistance pattern in the farms showed that isolates from all five farms recorded a $100 \%$ resistance to at least two (2) classes of antibiotics. A 100\% resistance was recorded for augmentin in all five (5) farms, while $100 \%$ resistance in four (4) farms was recorded for cloxacilin. Furthermore a $100 \%$ resistance against erythromycin and cefixime respectively was documented in three farms. Moreover resistance of $95 \%$ and $94 \%$ against erythromycin was recorded in farms $\mathrm{D}$ and $\mathrm{B}$ respectively. The least percentage resistance of $30 \%$ was against ciprofloxacin which occurred in farm $\mathrm{C}$. The antibiotic resistance pattern is highlighted in Figure 4.

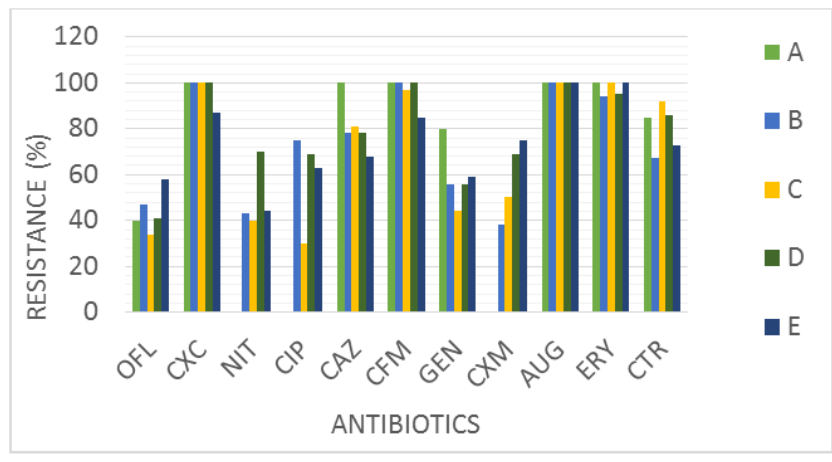

Figure 4. Antibiotics resistance pattern in the five farms.

Antibiotics resistance profile of bacterial isolates from individual farms differed from farm to farm. In farm A (Supplementary File 1), a 100\% resistance was recorded for cloxacilin, ceftazidime, cefixime, augmentin and erythromycin; $85 \%$ resistance towards ceftriaxone and the least resistance of $40 \%$ was towards ofloxacin. The mean percentage resistance against the panel of antibiotics tested was $89 \pm 9.9 \%$. On the other hand, a resistance of $100 \%$ against cloxacilin, cefixime and augmentin; $94 \%$ against erythromycin and the least resistance of 38\% against cefuroxime by the isolates was observed in farm B (Supplementary File 2). Also in the farm B, a mean percentage resistance of $74 \pm 17.6 \%$ was recorded against the antibiotics tested. Likewise the isolates from farm C (Supplementary File 3) exhibited $100 \%$ resistance against three antibiotics comprising cloxacillin, augmentin and erythromycin followed by a $97 \%$ and $92 \%$ resistance against cefixime and ceftriaxone respectively, and the least $30 \%$ resistance was against ciprofloxacin. Furthermore, the resistance pattern of isolates from farm D (Supplementary File 4), showed that percentage resistance against cloxacilin, cefixime and augmentin was $100 \%$ followed by $95 \%$ resistance against erythromycin while the least percentage resistance of $41 \%$ was against ofloxacin. In addition, antibiotics resistance pattern of the isolates from Farm E (Supplementary File 5) indicated a $100 \%$ resistance against augmentin and erythromycin, 94\% resistance against cefixime and a least percentage resistance of $44 \%$ against nitrofurantoin. A mean percentage resistance of $89 \pm 9.9(\%)$ and $74 \pm 17.6(\%)$ against the panel of antibiotics tested was recorded in Farms A and B respectively, while $68 \pm 20$ (\%), $78.3 \pm 20.4(\%)$ and $76.2 \pm 20.2(\%)$ was the mean percentage resistance observed in Farms C, D and E respectively (Supplementary Files 1-5).

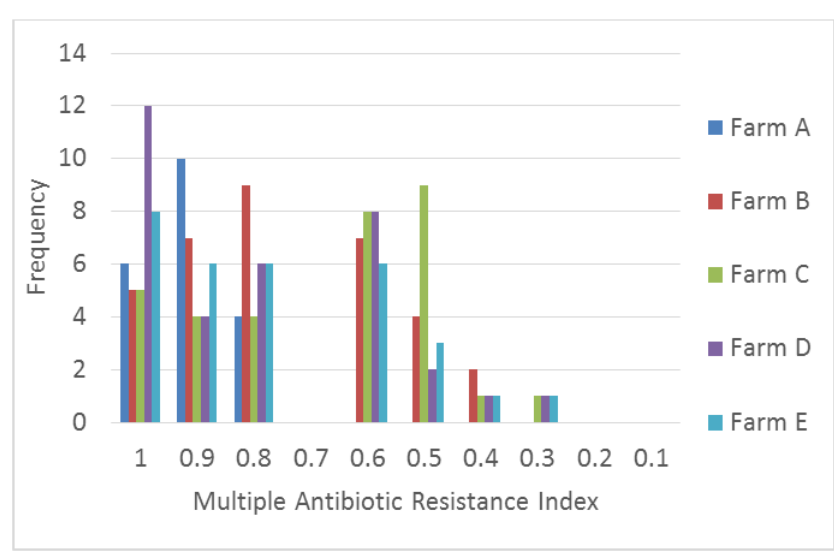

Figure 5. Frequency of Multiple Antibiotic Resistance Index.

The MARI of isolates from all farms ranged from 0.3 to 1 . Farm A had the highest average of $0.9 \pm 0.1$, followed by an average of $0.8 \pm 0.2$ for Farms B, D and E respectively, and an average of $0.7 \pm 0.2$ for farm C (Supplementary Files 1-5). Frequency distribution of the MARI showed that Farm D had the highest frequency (12) of the MARI value 1. Bacterial isolates from all farms with MARI 1 comprised E. coli, and the genera Salmonella, Proteus, Staphylococcus, Corynebacterium, Enterobacter, Bacillus, Klebsiella, 
Pseudomonas, as well as Enterobacter. The least MARI of 0.3 was recorded for Staphylococcus sp., Enterobacter sp. and E. coli in Farms C, D and E respectively. The result is presented in Figure 5.

\section{Discussion}

The level of microbial contamination in poultry farms is one of the most important sanitary and hygienic indicators. The main sources of microorganisms in poultry houses are birds, droppings, litter, feed, ventilation air, as well as employees [20].

The heterotrophic bacterial count (HTB) in this study showed the highest to be $2.05 \times 10^{7} \mathrm{cfu} / \mathrm{ml}$ which was from water sample, while another high HTB count of $2.01 \times 10^{7}$ $\mathrm{cfu} / \mathrm{g}$ was from feed sample. However, the droppings had the least bacterial count of $1.46 \times 10^{5} \mathrm{cfu} / \mathrm{g}$. According to Reference [21], water troughs left for 3-5 days uncleaned have increased high bacterial loads, which may be from regurgitated feed particles or from source water. Contrary to this findings however, Reference [22] reported a higher bacterial counts in litter than feed samples. Another study also reported a higher bacterial count in poultry litter than in soil samples of poultry farms and agricultural land [23]. Although a hundred and fifty-one (151) isolates comprising eleven (11) genera were isolated from the farms, these may not be a complete representation of the bacterial population due to viable but non-culturable (VBNC) condition of some bacteria. The highest frequency of $E$. coli, recorded in this study is similar to findings from previous studies on other poultry farms in Nigeria [22, 24] and other parts of the world [23, 25, 26]. This is not surprising since $E$. coli is ubiquitous in the gastrointestinal tracts of warm-blooded animals [27]. E. coli is an etiologic agent of collibacillosis, a global bacterial disease of poultry which is transmissible to humans; while some are capable of traversing into organs, causing fatal disease in birds [28]. Other bacterial species of high incidence in this study, by decreasing order include Bacillus sp., Salmonella sp., Klebsiella sp., Staphylococcus sp., Proteus sp. Shigella and Enterobacter sp. Bacillus species may include both free living non-pathogenic and pathogenic species including $B$. cereus which causes food poisoning and B. anthracis, the etiologic agent of anthrax. Salmonella species are wide spread in poultry production and are the etiological agent of salmonellosis and pullorum disease, characterized by high mortality and reduction in productivity [29]. Klebsiella species have commonly been isolated from both poultry birds, litters, droppings, feed, water and the poultry environment [23 30-32]. Common pathogenic Klebsiella in humans and animals include $K$. oxytoca, $K$. pneumonia and $K$. varricola [30]. Staphylococcal infection can cause food poisoning in man when contaminated poultry meat is consumed. Escherichia coli, Salmonella gallinarum, and Proteus species have been implicated in chick mortality. Moreover, Salmonella and Proteus; Streptococcus pluranimalium and Staphylococcus saprophyticus; S. aureus; faecal Enterococci, E. coli, S. typhi, S. aureus and non-coagulase staphylococci have all been identified in poultry air environment, hatcheries, and water sources used in poultry $[33,34]$. Hence the poultry environment could serve as reservoir of pathogenic bacteria with the associated public health risks.

Poultry flocks are often raised under intensive conditions using large amounts of antimicrobials to prevent and to treat disease, as well as for growth promotion. For instance, the antibiotic usage pattern observed in a survey of poultry farms in Nigeria showed that poultry farmers relied heavily on antimicrobial medications, and most farms were multi-drug users for therapeutic, prophylactic and for growth promotion $[35,3]$. The use of antimicrobials in intensive poultry production is becoming increasingly common at smaller scales within low-resource settings because of its high output of meat and egg products, and this is expected to intensify with the increased transition of low-to middle income countries to high incomes with the attendant demand for increased sources of animal protein [36]. However antimicrobial resistance (AMR) has become a global health threat, and nontherapeutic antimicrobial usage in animal production is one of its contributing sources [37, 38]. It has been suggested that the use of nontherapeutic antimicrobials be eliminated due to the substantial and increasing volume of direct and indirect evidence reporting animal-to-human transmission of resistant bacteria, and the growing environmental load of resistance [37].

In this study, isolates from all the five farms sampled showed varying percentage resistance to the eleven antibiotics tested. A complete $(100 \%)$ resistance was recorded for augmentin, cloxacilin, erythromycin and cefixime in five (5), four (4), and three (3) farms respectively. The least percentage resistance of $30 \%$ (against ciprofloxacin) was recorded in only one farm (Farm C). All five farms recorded a 100\% resistance to at least two (2) classes of antibiotics. Resistance against fluoroquinolones as recorded in this study is of great concern since they are the commonest class of antibiotics used in the poultry farms, they also serve as farmers' option in cases of refractory bacterial infections caused by bacterial resistance to the conventional older generation frontline antibiotics, and are also known to be highly successful and strategic in the treatment of infections such as salmonellosis caused by multiresistant Salmonella serotypes [35]. An earlier report on poultry farms droppings in Ile Ife documented $E$. coli strains to be more resistant than staphylococci and showed $100 \%$ resistance to nalidixic acid and amoxicillin but with lower resistance to gentamicin [3]. Another study on poultry droppings in Ilorin documented all the Gram positive bacteria to be resistant to ceftazidime, cefuroxime, ceftriaxone, cloxicillin and Amoxycillin-clavulinate (augmentin) while all the Gram negative bacteria were resistant to ceftazidime, gentamcin and Amoxycillin-clavulinate; and S. aureus and Microbacterium holobium were resistant to all the antibiotics tested [39]. A report on poultry farms in India stated more than $70 \%$ resistant $E$. coli to co-trimoxazole, penicillins and fluoroquinolones; $50-70 \%$ resistance against cefuroxime and ceftriaxone and less than $30 \%$ resistance to aminoglycosides [23]. Elsewhere, a statistically significant difference in 
antibiotic resistant $E$. coli between both of conventional, no antibiotics poultry farming and chicken from humane family owned production schemes, with resistance against two of the antibiotics, ampicillin and erythromycin, has been reported [40]. Production birds, including broilers and laying hens, were reported to have high levels of resistance and a notably higher proportion of resistant isolates than household birds [41].

MARI tool is used to reveal the spread of bacteria resistance in a given population [19]. Any MARI value above 0.20 implies that such bacterial strain originates from an environment where several antibiotics are used or misused, have been exposed to several antibiotics, and have thereby developed resistance to these antibiotics [19, 42]. The bacterial isolates with MARI value of 1 in this study includes E. coli, and eight other genera comprising Salmonella, Proteus, Staphylococcus, Corynebacterium, Enterobacter, Bacillus, Klebsiella, as well as Pseudomonas. This implies exposure of these isolates to several antibiotics of which they have developed high resistance. This study corroborates an earlier report of a multiple antibiotics resistance of bacterial isolates from Farm A with MARI range of 0.1 to 1 . Higher susceptibility to quinolone (ofloxacin) and aminoglycosides (gentamicin) recorded in this study however, is in contrast with the quinolones comprising ofloxacin, ciprofloxacin and pefloxacin which were the most effective of all the antibiotics used in that study [43]. Reference [24] reported $65.4 \%$ of the bacterial isolates from chicken litter as resistant to multiple antibiotics, with a MARI $\geq 0.2$. Multidrug resistant bacteria have been found in poultry, poultry feed, water, poultry products, carcasses, litter and droppings [44, 45]. Reference [32] reported that commercial day-old chicks in Nigeria are already colonized by multidrug-resistant coliforms. These not only serve as sources of environmental reservoir of antibiotic resistance genes but also exposure potential to the farmers. For instance, a significantly higher antibiotics resistance prevalence and multidrug resistant $E$. coli has been reported among poultry workers [45].

Despite global control strategies, proper veterinary monitoring especially in the predominately small-scale poultry farming in Nigeria has been a challenge [22]. Moreover Nigeria also faces a hazard of poor antibiotic prescription monitoring and prescription-only medicines, including antimicrobials that are routinely sold Over-The-Counter (OTC) in pharmacies and by patent proprietary medicines vendors [17]. Furthermore, the high bacterial load observed, and the high incidence of pathogenic bacterial genera is a further indication of the potential public health hazard that might be associated with poultry farms.

Apart from the direct danger posed to humans by consumption of contaminated poultry products, there is also the risk of indirect transmission of the resistant genes. These would reduce the treatment options, increase the cost of treatment or risk of treatment failure thereby leading to a longer hospital stay. Additionally, poultry wastes are used in fish farming as feed, and also as soil enrichment manure. Study has shown that poultry waste can serve as environmental reservoirs of multiple antibiotic resistant bacteria therefore their indiscriminate use and dumping in the environment could constitute health risks from drug resistant zoonotic pathogens [46].

\section{Conclusion}

Although further promotion of intensive poultry farming could address issues of food security, it may also increase risks of AMR exposure to poultry, other domestic animals, wildlife, and human populations. Given that intensively raised poultry and the environment can serve as reservoirs for AMR, constant surveillance is needed for assessment of the impacts on humans, other animals, and the environment at large. This study is a further indication that poultry farms represents an important reservoir of antibiotic resistance genes. It also serves as a pointer to the need for enforcement of regulatory antibiotics use in poultry farming by the government, and controlled usage by all stakeholders.

\section{Acknowledgements}

The authors are appreciative of the cooperation and support of the poultry farm owners and Technical Staff of Biological Sciences Department, College of Natural and Applied Sciences, Oduduwa University Ipetumodu, Ile Ife, Osun State, Nigeria.

\section{References}

[1] Bolan, N. S., Szogi, A. A., Chuasavathi T., Seshadri, B. V., Rothrock, M. J., \& Panneerselvam, P. (2010). Uses and management of poultry litter. W Poultry Sci J 66, 673-698.

[2] Food and Agricultural Organization, FAO (2017). Gateway to poultry production and products. http://www.fao.org/poultry-species (Accessed 07/06/2021).

[3] Awogbemi, J., Adeyeye, M., \& Akinkunmi, E. O. (2018) A survey of antimicrobial agents usage in poultry farms and antibiotic resistance in Escherichia coli and Staphylococci isolates from the poultry in Ile-Ife, Nigeria. J Infect Dis Epidemiol 4, 047. https://doi.org/10.23937/2474-3658/1510047 Food and Agricultural Organization.

[4] FAO (2014). Sources of the world's meat supply in 2012. http://www.fao.org/poultry-production (Accessed 17/05/2021).

[5] Timothy, F., Landers, B. C., Thomas, E. W., \& Elaine, L. L. (2012). A Review of antibiotic use in food animals: Perspective, policy, and potential. Pub Health Rep 127, 5-7.

[6] Adebayo, O. O. \& Adeola, R. G. (2005). Socio-economic factors affecting poultry farmers in Ejigbo local government area of Osun State. J Hum Ecol 18, 39-41.

[7] McEwen, S. A., \& Fedorka-Cray, P. J. (2009). Antimicrobial use and resistance in animals. Clin Infect Dis Suppl 3, 93-106.

[8] Bogaard, A. E. \& Stobberingh, E. E. (2012). Epidemiology of resistance to antibiotics. Links between animals and humans. Int J Antimicrob Agent, 14, 327-335. 
[9] Jallailudeen, R. L., Saleh, M. J., Yaqub, A. G., Amina, M. B. Yakaka, W. \& Muhammad, M. (2015). Antibiotic Residues in Edible Poultry Tissues and Products in Nigeria: A Potential Public Health Hazard. Int J Ani Vet Adv 7, 55-61.

[10] Van Looveren, M., Daube, G., De Zutter, L., Dumont, JM., Lammens, C., Wijdooghe, P., Vandamme, M., Jouret, M., Cornelis, M. \& Goossens, H. (2010). Antimicrobial susceptibilities of Campylobacter strains isolated from food animals in Belgium. J. Antimicrob. Chemo. 48, 235-240.

[11] Hayes, J. R., English, L. L., Carr, L. E. and Wagner, D. D. (2004). Multiple-antibiotic resistance of Enterococcus spp. isolated from commercial poultry production environments. Appl Environ Microbial 70, 6005-6011.

[12] Kolář, M., Pantůček, R., Bardoň, J., Vágnerová, I., Typovská, H., Válka, I. \& Doškar̆, J. (2002). Occurrence of antibiotic-resistant bacterial strains isolated in poultry. Vet. Medcine Czech. 47, 52-59.

[13] Rushton, J., Stärk, K. \& Pinto, F. J. (2014). Antimicrobial resistance: The uses of antimicrobials in the livestock sector. OECD Food Agric Fisheries, 68, 16-21.

[14] Kolawole, I. S., Alaga, T. A., Ogunyemi, S. A., Popoola, S. A. \& Oloko-Oba, M. O. (2016). Street mapping of Ife metropolis, Osun state, Nigeria. J. Geograph Info System, 8, 387-395.

[15] Yanestria, S. M., Rahmaniar, R. P., Wibisono, F. J., Effendi, M. H. (2019). Detection of invA gene of Salmonella from milkfish (Chanos chanos) at Sidoarjo wet fish market, Indonesia, using polymerase chain reaction technique. Vet World; 12: 170-5. http://dx.doi.org/10.14202/vetworld.2019.170-175 (Accessed $12 / 06 / 2021)$

[16] Noel, K. R, \& John, H. G. Bergey's Manual of Systematic Bacteriology. Baltimore, USA: Wiliam \& Wilkins 1984; Vol. 1.

[17] Fakorede, C. N., Fatokun, E. N., Philip-Kantiok, B., Iwu, C. J. \& Jaja, I. F. (2020). Bacteriological Quality and Antibiotics' Susceptibility Profile of Small-medium Scale Commercial Fish farms in Nigeria. The Open Agric J, 14, 198-208.

[18] CLSI (2017). Performance Standards for Antimicrobia Susceptibility Testing. 27th Editi. Wayne, USA: Clinical and Laboratory Standards Institute 2017.

[19] Krumperman, P. H. (1983). Multiple Antibiotic Resistance Indexing of Escherichia coli to identify high-risk sources of fecal contamination of foods. Appl Envt Microbiol, 46, 165-170.

[20] Witkowska, D. \& Sowińska, J. (2017). Identification of Microbial and Gaseous Contaminants in Poultry Farms and Developing Methods for Contamination Prevention at the Source, Poultry Science, Milad Manafi, IntechOpen, DOI: $10.5772 / 64891$

https://www.intechopen.com/books/poultry-science/identificat ion-of-microbial-and-gaseous-contaminants-in-poultry-farmsand-developing-methods-for-con (Accessed 19/04/2021).

[21] Folorunso, O. R., Sule, K., Onibon, V. O. (2014). Poultry farm hygiene: microbial quality assessment of drinking water used in layer chickens managed under the battery cage and deeply litter systems at three poultry farms in southern Nigeria. Pak J Biol Sci, 17; 74-79.

[22] Cookey, T. I. \& Otokunefor, K. (2016). Poultry Environment as a Reservoir of Antimicrobial Resistant Bacteria - A Nigerian Story. Brit Microbiol Res, J, 17: 1-11. Article no. BMRJ.28601.
[23] Bhushan, C., Khurana, A., Sinha, R. \& Nagaraju, M. (2017). Antibiotic resistance in poultry environment spread of resistance form poultry farm to agricultural field. Centre for Science and Environment. New Delhi.

[24] Olonitola, O. S., Fahrenfeld, N. \& Pruden, A. (2015). Antibiotic resistance profile among mesophilic aerobic bacteria in Nigerian chicken litter and associated antibiotic resistance genes. Poultry Sci, 94, 867-874.

[25] Mwambete, K. D. \& Wilbard, S. S. (2015). Antimicrobial resistance profiles of bacteria isolated from chicken droppings in Dar Es Salaam. Int J Pharm Pharma Sci, 7, 268-398.

[26] Trawińska, B., Chmielowiec-Korzeniowska, A., Nowakowicz-Dębek, B., Tymczyna, L., Bombik, T., Pyrz, M., Tymczyna-Sobotka, M. (2016). Evaluation of microbial contamination of feces and soil on a laying-hen farm depending on sampling site and season. R Bras Zootec, 45 (4) https://doi.org/10.1590/S1806-92902016000400007 (Accessed $12 / 06 / 2021)$.

[27] Nhung, N. T., Chansiripornchai, N. \& Carrique-Mas, J. J. (2017). Antimicrobial Resistance in Bacterial Poultry Pathogens: A Review. Front Vet Sci 10 https://doi.org/10.3389/fvets.2017.00126 (Accessed 07/05/2021)

[28] Ibrahim, RA, Cryer, TL, Lafi, SQ, Basha, E, Good, L, Tarazi, YH (2019). Identification of E. coli from broiler chickens in Jordan, their antimicrobial resistance, gene characterization and the associated risk factors. BMC Vet Res, 15, 1- 16.

[29] Barrow, P. A. \& Freitas Neto O. C. (2011). Pullorum disease and fowl typhoid-new thoughts on old diseases: a review. Avian Pathol, 40, https://doi.org/10.1080/03079457.2010.542575

$1-13$

30] Fielding, B. C., Mnabisa, A., Gouws, P. A., \& Morris, T. (2012) Antimicrobial-resistant Klebsiella species isolated from free-range chicken samples in an informal settlement. Arch Med Sci, 8, 39-42.

[31] Omoya, F. O. \& Ajayi, K. O. (2016). Antibiotic resistance pattern of pathogenic bacteria isolated from poultry droppings in Akure, Nigeria. FUTA J Res Sci, 12, 219-227.

[32] Okorafor, O. N.; Anyanwu, M. U.; Nwafor, E. O.; Anosa, G. N.; Udegbunam, R. I. (2019). Multidrug-resistant enterobacteria colonize commercial day-old broiler chicks in Nigeria. Vet World, 12, 418-423.

[33] Munang'andu, H M, Kabilika, S. H., Chibomba, O., Munyeme, M. \& Muuka, G. M. (2012). Bacteria isolations from broiler and layer chicks in Zambia. J Patho, 2012 Article ID 520564 https://doi.org/10.1155/2012/520564 (Accessed 07/05/2021).

[34] Osei, F. B., Boamah, V. E., Agyare, C., Abaidoo, R. C. (2019). Physicochemical properties and microbial quality of water used in selected poultry farms in the Ashanti Region of Ghana. The Open Microbiol J, 13, 121-127. https://DOI:10.2174/1874285801913010121 (Accessed 07/05/2021).

[35] Oluwasile, B. B., Agbaje, M., Ojo, O. E., Dipeolu, M. A. (2014). Antibiotic usage pattern in selected poultry farms in Ogun state. Sokoto J Vet Sci, 12, 45-50.

[36] Hedman, H. D., Vasco, K. \& Zhang, L. (2020). A Review of Antimicrobial Resistance in Poultry Farming within Low-Resource Settings Animals, 10, 1264. https://doi:10.3390/ani10081264 (Accessed 17/05/2021). 
[37] Marshall, B. M. \& Levy, S. B. (2011). Food Animals and Antimicrobials: Impacts on Human Health. Clin Microbiol Rev, 24, 718-733.

[38] World Health Organization, WHO. (2014). Antimicrobial Resistance Global Report on Surveillance. Geneva: 256. Retrieved from: http://www.who.int/drugresistance/documents/surveillancerep ort/en/ on 15th April, 2018.

[39] Sule, I. O., Olorunfemi, A. A. \& Otori, A. O. (2019). Mycological and bacteriological assessment of poultry droppings from poultry pens within Ilorin, Kwara, Nigeria. Sci World J, 14, 11-16.

[40] Sanchez, H. M., Whitener, V. A., Thulsiraj, V., Amundson, A., Collins, C., Duran-Gonzalez, M. et al. (2020). Antibiotic resistance of Escherichia coli isolated from conventional, no antibiotics, and humane family owned retail Broiler chicken meat. Animals, 10, 1-17.

[41] Braykov, N. P., Eisenberg, J. N. S., Grossman, M., Zhang, L., Vasco, K., Cevallos, W. et al. (2016). Antibiotic resistance in animal and environmental samples associated with small-scale poultry farming in northwestern Ecuador. mSphere1: e00021-15. https://doi:10.1128/mSphere.00021-15 (Accessed 17/05/2021).
[42] Ekwealor, P. A., Ugwu, M. C., Ezeobi, I., Amalukwe, G., Ugwu, B. C., Okezie, U., Stanley, C. \& Esimone, C. (2016). Antimicrobial evaluation of isolates from urine specimen of patients with complaints of urinary tract infections in Awka, Nigeria. Int J Microbiol, 2016: 9740273. doi: $10.1155 / 2016 / 9740273$.

[43] Adeleke, E. \& Omafuvbe, B. (2011). Antibiotic resistance of aerobic mesophilic bacteria isolated from poultry faeces. Res. J. Microbiol., 6, 356-365.

[44] Agyare, C., Boamah, V. E., Zumbi, C. N., Osei,, F. B. (2018). Antibiotic use in poultry production and its effects on bacterial resistance-A Global Threat. IntechOpen. 79371: 33-44. https://doi:10.5772/intechopen.79371 (Accessed 20/02/2021).

[45] Aworh, M. K., Kwaga, J., Okolocha, E., Mba, N. \& Thakur, S. S. (2019). Prevalence and risk factors for multi-drug resistant Escherichia coli among poultry workers in the Federal Capital Territory, Abuja, Nigeria. PLoS ONE, 14, e0225379. https://doi.org/10.1371/journal.pone.0225379

[46] Adelowo, O. O., Ojo, F. A. \& Fagade, O. E. (2009). Prevalence of multiple antibiotic resistance among bacterial isolates from selected poultry waste dumps in Southwestern Nigeria. World J Microbiol Biotech, 25, 713-719. 